Check for updates

Cite this: RSC Adv., 2018, 8, 26928

Received 12th June 2018

Accepted 19th July 2018

DOI: $10.1039 / \mathrm{c} 8 \mathrm{ra05057k}$

rsc.li/rsc-advances

\section{Evaluation of performance and microbial community successional patterns in an integrated OCO reactor under $\mathrm{ZnO}$ nanoparticle stress}

\author{
Zhenghui Liu, (DD ab Huifang Zhou, ${ }^{a}$ Jiefeng Liu, ${ }^{a}$ Mei Huang, ${ }^{a}$ Xudong Yin, ${ }^{a b}$ \\ Zhisen Liu, ${ }^{a b}$ Yufeng Mao, ${ }^{a}$ Wenyu $\mathrm{Xie}^{\mathrm{ab}}$ and Dehao Li ${ }^{\star a b}$
}

An integrated OCO reactor was used to investigate the performance and microbial community successional changes under long-term exposure to relatively low levels of ZnO nanoparticles (NPs). Relatively higher concentrations of $\mathrm{ZnO}$ NPs $\left(1.5 \mathrm{mg} \mathrm{L}^{-1}\right)$ could adversely affect the nitrogen and phosphorus removal in the reactor. The diversity and richness of the microbial communities chronically declined with an increasing concentration of ZnO NPs higher than $1.5 \mathrm{mg} \mathrm{L}^{-1}$. With the elevated $\mathrm{ZnO}$ NPs, the phyla abundances of Proteobacteria, Firmicutes and Actinobacteria decreased slightly, whereas those of Bacteroidetes and Acidobacteria increased. Bacteroidetes and Proteobacteria were the predominant phyla in each phase (with a variation in abundance), together with some common taxa responses to ZnO NP stress as revealed by Venn diagram analysis. Some genera associated with the removal of nitrogen and phosphorus, such as Acinetobacter, Stenotrophomonas and Pseudomonas, decreased significantly. The present results are significant for expanding our understanding of the functional performance and microbial community successions of activated sludge which has experienced long-term exposure to environmentally relevant concentrations of ZnO NPs.

\section{Introduction}

With the rapid development of nanotechnology, the application of engineered nanomaterials (ENMs) in a variety of industrial products and consumer goods has accelerated. Among ENMs, ZnO nanoparticles (ZnO NPs) together with titanium dioxide NPs and silver NPs are the most frequently used inorganic species in these industrial products and consumer goods. ${ }^{1}$ Taking into consideration that NPs might enter into domestic sewage and industrial wastewater systems, their potential effects on the environment and human health have raised increasing concerns.

ZnO NPs are widely used in paints, coatings, cosmetics, photocatalysts, therapeutics, drug delivery systems and semiconductors, due to their antimicrobial, catalytic and ultravioletprotective properties. ${ }^{2}$ Previous studies reported the occurrence of ZnO NPs in wastewater treatment plants (WWTPs). ${ }^{3,4}$ Considering that activated sludge plays a crucial role in biological wastewater treatment, the interaction of activated sludge with NPs may compromise the performance of WWTPs. Currently, most reports have focused on the toxic effects of $\mathrm{ZnO}$

${ }^{a}$ School of Environmental and Biological Engineering, Guangdong University of Petrochemical Technology, Maoming, Guangdong 525000, China. E-mail: dehlee@ 163.com

${ }^{b}$ Technology Research Center for Petrochemical Resources Clean Utilization of Guangdong Province, Maoming, Guangdong 525000, China
NPs on specific bacteria, such as Escherichia coli ${ }^{5}$ and Pseudomonas stutzeri. ${ }^{6}$ The impact of ZnO NPs on the microbial communities of the activated sludge has also been investigated recently. Based on high-throughput pyrosequencing, Wang et al. reported that the abundance of nitrite oxidizing bacteria (NOB) increased but the abundance of ammonium oxidizing bacteria (AOB) and denitrifying bacteria was relatively stable in a membrane bioreactor (MBR); Z Zhang et al. reported the toxicity effect of ZnO NPs on nitrogen removal and microbial communities in a CANON reactor. ${ }^{8}$

Although valuable findings have been documented based on current organismal studies, it is necessary to present a comprehensive understanding that microbial communities act as a whole in maintaining the key functions of a complex environment from an ecological perspective. Several studies have focused on the long-term effects of elevated ZnO NP concentrations on the microbial communities in wastewater treatment systems. ${ }^{8-10}$ In these studies, the ZnO NP concentrations used were relatively high (over $5 \mathrm{mg} \mathrm{L}^{-1}$ ), although admittedly, high concentrations of NPs are required to function in traditional toxicity assays,${ }^{11}$ meanwhile the environmentally relevant concentration of NPs increases inevitably. ${ }^{9}$ Given that the highest concentration of ZnO NPs in WWTPs reaches $300 \mu \mathrm{g}$ $\mathrm{L}^{-1},{ }^{4}$ and $5 \mathrm{mg} \mathrm{L}^{-1}$ of ZnO NPs causes no inhibitory effects on the microbial growth, ${ }^{8}$ we hypothesized that relatively lower concentrations of NPs may have an unpredictable influence on the activated sludge systems over time. Research should provide 
insight into the long-term effects of environmentally relevant concentrations (or higher by about an order of magnitude) of ZnO NPs on the ecological function of microbial communities in activated sludge.

In the present study, activated sludge systems in an integrated OCO reactor (an anaerobic/anoxic/oxic $\left(\mathrm{A}^{2} / \mathrm{O}\right)$ process with a shape similar to the letters of the alphabet "OCO") ${ }^{\mathbf{1 2}}$ were treated with various concentrations of ZnO NPs $\left(0.25 \mathrm{mg} \mathrm{L}^{-1}\right.$, $0.8 \mathrm{mg} \mathrm{L}^{-1}, 1.5 \mathrm{mg} \mathrm{L}^{-1}$ and $4 \mathrm{mg} \mathrm{L}^{-1}$ ) for a performance period of 80 days, and the shifts in the microbial communities were revealed using Illumina Miseq pyrosequencing of the 16S rRNA gene. The objectives of this study were as follows: (1) to evaluate the ecotoxicity of ZnO NPs on wastewater treatment systems, and (2) to illustrate the responses of microbial communities to the long-term exposure of relatively lower concentrations of ZnO NPs.

\section{Materials and methods}

\subsection{Experimental set-up and operation}

The integrated OCO reactor with an effective volume of $240 \mathrm{~L}$ has been operating for more than one year, and the reactor has been described previously. ${ }^{12}$ The synthetic wastewater consisted of glucose, sucrose, soluble starch, $\mathrm{NH}_{4} \mathrm{HCO}_{3}, \mathrm{KH}_{2} \mathrm{PO}_{4}$, and a trace element solution (including $\mathrm{MgCl}_{2}, \mathrm{CaCl}_{2}, \mathrm{MnSO}_{4}$, $\mathrm{CoCl}_{2}, \mathrm{CuSO}_{4}, \mathrm{FeSO}_{4}$ and $\mathrm{H}_{3} \mathrm{BO}_{3}$ ) as previously reported..$^{13}$ The parameters $\mathrm{COD}, \mathrm{TN}$ and $\mathrm{TP}$ of the synthetic wastewater were adjusted to about $300 \mathrm{mg} \mathrm{L^{-1 }}, 37 \mathrm{mg} \mathrm{L}^{-1}$ and $5 \mathrm{mg} \mathrm{L}^{-1}$, respectively. The hydraulic retention time was $12 \mathrm{~h}(1.6 \mathrm{~h}$ for the anaerobic zone, $3.3 \mathrm{~h}$ for the anoxic zone, $4.8 \mathrm{~h}$ for the aerobic zone, and $2.3 \mathrm{~h}$ for the mixed zone and sedimentation tanks). The influences of the ZnO NPs on nutrient (nitrogen and phosphorus) removal and on the microbial community were investigated after the reactor reached a relatively steady state.

\subsection{Nanoparticle and preparation of nanoparticle suspensions}

ZnO nanoparticles were purchased from Shanghai Hansi Chemical Industry Co. Ltd (Shanghai, China), and the average diameter of the nanoparticles was about $30 \mathrm{~nm}$. The size and shape of the nanoparticles were also characterized via transmission electron microscopy (TEM) images using an FEI Tecnai G20 microscope with a voltage of $200 \mathrm{kV}$ (FEI company, USA). A nanoparticle stock suspension of $100 \mathrm{mg} \mathrm{L}^{-1} \mathrm{ZnO}$ NPs was concocted by adding $0.1 \mathrm{~g}$ ZnO NPs to $1 \mathrm{~L}$ Milli-Q water, with sonication $(300 \mathrm{~W})$ for $20 \mathrm{~min}$. Then, various concentrations of ZnO NP suspensions were prepared by diluting the stock suspension with Milli-Q water.

\subsection{Batch experiments with exposure to ZnO NPs}

The integrated OCO reactor was initiated with the inoculation of activated sludge from a full-scale wastewater treatment plant in Maoming, Guangdong, China. Prior to the addition of ZnO NP suspensions in the influent, the integrated OCO reactor had operated continuously for $20 \mathrm{~d}$ maintaining a steady operation performance. Then, ZnO NP suspensions were freshly prepared and added to the reactor with final concentrations of $0.25 \mathrm{mg} \mathrm{L}^{-1}, 0.8 \mathrm{mg} \mathrm{L}^{-1}, 1.5 \mathrm{mg} \mathrm{L}^{-1}$ and $4 \mathrm{mg} \mathrm{L}^{-1}$ for continuous treatment, and the duration time of each treatment was $20 \mathrm{~d}$.

\subsection{Analytical methods}

The temperature, dissolved oxygen (DO) and $\mathrm{pH}$ values were measured using portable apparatus with specific probes (WTW, Germany). $\mathrm{NH}_{4}{ }^{+}-\mathrm{N}, \mathrm{NO}_{2}{ }^{-}, \mathrm{NO}_{3}{ }^{-}$, the total phosphorus (TP) and the chemical oxygen demand (COD) were measured according to standard methods. ${ }^{\mathbf{1 4}}$ The total nitrogen (TN) was calculated as the sum of $\mathrm{NH}_{4}{ }^{+}-\mathrm{N}, \mathrm{NO}_{2}{ }^{-}$and $\mathrm{NO}_{3}{ }^{-}$.

\subsection{Pyrosequencing and phylogenetic assignment}

The total genomic DNA from each sludge sample was extracted and purified using the FastDNA $®$ Spin Kit for Soil (MP-Bio, USA) according to the manufacturer's instructions. The DNA concentration and quality were detected with $1 \%$ agarose gel electrophoresis and a NanoDrop Spectrophotometer. The partial 16S rRNA genes were amplified with barcoded primers 515F (5'-GTGCCAGCMGCCGCGGTAA-3 $\left.{ }^{\prime}\right)$ and 909R ( $5^{\prime}$ CCCCGYCAATTCMTTTRAGT- ${ }^{\prime}$ ), and pyrosequencing was carried out using an Illumina Miseq sequencing platform. ${ }^{15}$ More than 10000 sequences with a $350 \mathrm{bp}$ length were obtained from each sample. The aligned sequences were used for a chimera check using the Uchime algorithm. ${ }^{16}$ Taxonomic classifications were performed using the Ribosomal Database Project classifier ${ }^{17}$ with a set confidence threshold of $80 \%$, and the operational taxonomic units (OTUs) were defined at a $3 \%$ dissimilarity cutoff. The Shannon diversity index, Chao 1 index, ACE index and Simpson index were analyzed by the QIIME software package. The similarities and differences among these communities were analyzed through Venn diagrams with shared and unique OTUs. ${ }^{18}$

\section{Results and discussion}

\subsection{Effects of $\mathrm{ZnO}$ NPs on reactor performance}

The morphological characterizations of the ZnO NPs are shown in Fig. 1, and the average diameter of the nanoparticles was $30 \mathrm{~nm}$. The performance of the OCO reactor in each phase has been depicted in Fig. 2. During the whole experiment, the influent concentrations of ammonia and phosphorus were constantly kept around $37 \mathrm{mg} \mathrm{L}^{-1}$ and $5 \mathrm{mg} \mathrm{L}^{-1}$, respectively. The concentration of the ZnO NPs was increased step-wise during each phase except in phase P0 (which acted as the control).

For nitrogen removal, no nitrite accumulation was observed throughout the dosing phases, indicating that the oxidation of nitrite remained unaffected. The nitrogen removal rate (NRR) reached an average of $0.055 \mathrm{~kg} \mathrm{~m}^{-3} \mathrm{~d}^{-1}$ (Table 1) in P0 with effluent nitrate at $7.55 \mathrm{mg} \mathrm{L}^{-1}$ and a low ammonia level. Then in phase P1, the ZnO NP stock suspension was directly added to the reactor for a concentration of $0.25 \mathrm{mg} \mathrm{L}^{-1}$ in the system. The NRR increased and reached an average of $0.060 \mathrm{~kg} \mathrm{~m} \mathrm{~m}^{-3} \mathrm{~d}^{-1}$ (Table 1), and this result was mainly attributed to the additional removal of nitrate, as $\mathrm{Zn}^{2+}$ ions can be released from the $\mathrm{ZnO}$ 


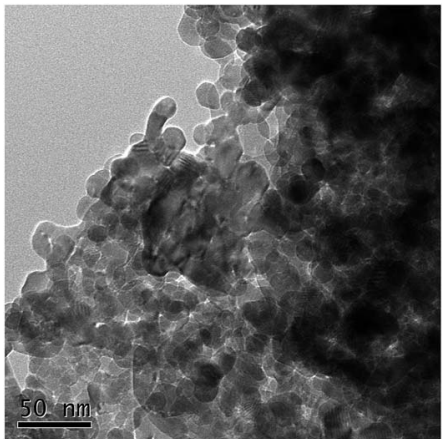

Fig. 1 High-resolution TEM image of the $\mathrm{ZnO}$ nanoparticles.

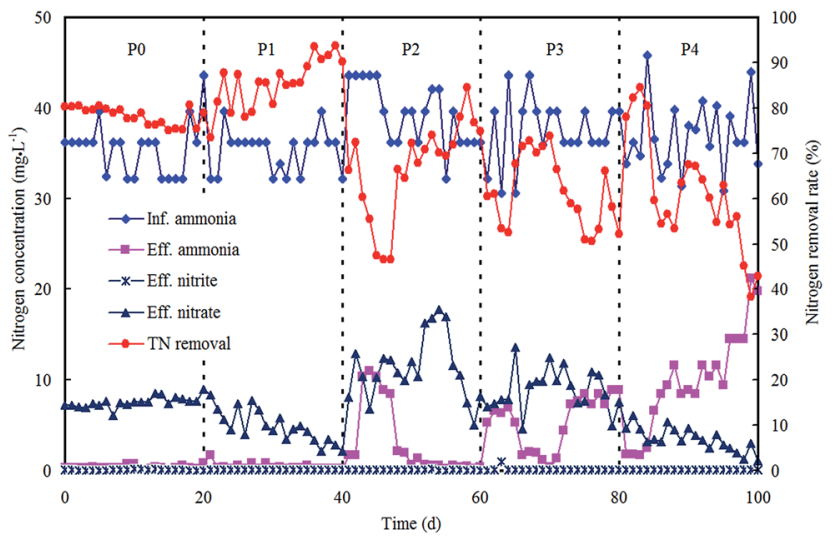

Fig. 2 Reactor performance on nitrogen removal in each phase with various concentrations of $\mathrm{ZnO}$ NPs.

NPs $\left(0.13 \mathrm{mg} \mathrm{\textrm {L } ^ { - 1 }} \mathrm{Zn}^{2+}\right.$ ions within $1 \mathrm{mg} \mathrm{L}^{-1} \mathrm{ZnO}$ NPs in wastewater), ${ }^{19}$ and low $\mathrm{Zn}^{2+}$ concentrations provide essential micronutrients for vital cofactors of metalloproteinases and certain enzymes thereby enhancing the bioactivities of nitrifiers and denitrifiers. ${ }^{20}$ Subsequently, the ZnO NP concentration was further increased to $0.8 \mathrm{mg} \mathrm{L}^{-1}$ in phase $\mathrm{P} 2$, and the NRR decreased significantly to an average of $0.049 \mathrm{~kg} \mathrm{~m}^{-3} \mathrm{~d}^{-1}(p<$ $0.05)$; both the ammonia and nitrate in the effluent presented an increasing trend. Then in phase $\mathrm{P} 3$, the ZnO NP concentration was further increased to $1.5 \mathrm{mg} \mathrm{L}^{-1}$ and the NRR exhibited a small decrease $\left(0.047 \mathrm{~kg} \mathrm{~m}^{-3} \mathrm{~d}^{-1}\right)$. This indicated that nitrifiers were significantly suppressed. Finally, in phase P4, as the ZnO NP concentration was increased to $4 \mathrm{mg} \mathrm{L}^{-1}$, the NRR remained almost unchanged $\left(0.047 \mathrm{~kg} \mathrm{~m}^{-3} \mathrm{~d}^{-1}\right)$, meanwhile with a decline in the effluent nitrate and a remarkable increase

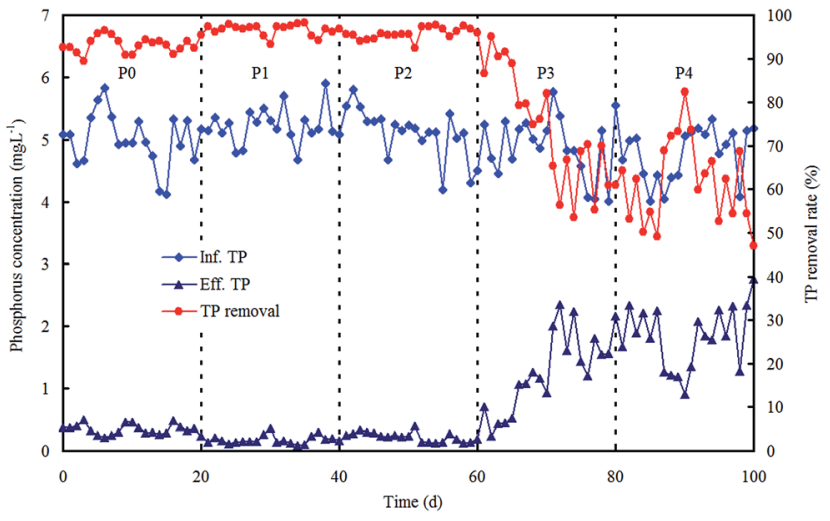

Fig. 3 Reactor performance on phosphorus removal in each phase with various concentrations of $\mathrm{ZnO} N P s$.

in the effluent ammonia, the ammonia removal rate had dramatically decreased to $41.48 \%$ by the last day. The decrease in the ammonia removal rate may be due to a long-lasting inhibition of nitrification, which was strengthened by the accumulative effect of the ZnO NPs. These results coincided with previous studies which proved that ammonia removal is inhibited by inhibition of the respiration of nitrifying bacteria ${ }^{21}$ or enzyme activity. ${ }^{22}$

For phosphorus removal, TP removal rate was kept above 90\% in phases P0, P1 and P2 (Fig. 3). This implies the negligible influence of the ZnO NPs on TP removal below a concentration of $0.8 \mathrm{mg} \mathrm{L}^{-1}$. When the concentration of ZnO NPs increased to $1.5 \mathrm{mg} \mathrm{L} \mathrm{L}^{-1}$ or higher, TP removal dramatically decreased. These results illustrate that the growth and activity of polyphosphate accumulating organisms (PAOs) are inhibited through the anaerobic release and aerobic uptake of phosphorus, thereby phosphorus removal clearly drops. ${ }^{23,24}$ However, COD removal was unaffected during the whole experimental period (data not shown). A previous study also reported that COD removal was not impacted adversely until the concentration of ZnO NPs reached as high as $68 \mathrm{mg} \mathrm{L}{ }^{-1} \cdot{ }^{25}$

\subsection{Responses of the microbial community successional patterns}

3.2.1 Effects of ZnO NPs on microbial community diversities. To further understand the effect of ZnO NPs on the bacterial community diversity and richness in the reactor during long-term exposure, high-throughput sequencing was performed using an Illumina Miseq system. The Good's coverage values of five samples were about 0.9 , indicating that

Table 1 Operational conditions and nutrient removal performances (average data of each phase)

\begin{tabular}{|c|c|c|c|c|c|c|}
\hline Phase & Period (d) & ZnO NPs $\left(\mathrm{mg} \mathrm{L}^{-1}\right)$ & Inf. $\mathrm{NH}_{4}^{+}\left(\mathrm{mg} \mathrm{L}^{-1}\right)$ & $\operatorname{NRR}\left(\mathrm{kg} \mathrm{m}^{-3} \mathrm{~d}^{-1}\right)$ & $\Delta \mathrm{NO}_{3}{ }^{-} / \Delta \mathrm{NH}_{4}^{+}$ & MLVSS $\left(\mathrm{mg} \mathrm{L}^{-1}\right)$ \\
\hline P0 & $0-20$ & 0 & 35.5 & 0.055 & 0.217 & 2016 \\
\hline P1 & $21-40$ & 0.25 & 35.2 & 0.060 & 0.141 & 2163 \\
\hline P3 & $61-80$ & 1.5 & 37.5 & 0.047 & 0.285 & 1579 \\
\hline $\mathrm{P} 4$ & $81-100$ & 4.0 & 36.8 & 0.047 & 0.127 & 1261 \\
\hline
\end{tabular}


Table 2 Sequencing results of the sludge sample in different phases

\begin{tabular}{|c|c|c|c|c|c|c|}
\hline Sample & Sequence numbers & OTU number & Shannon index & Chao1 index & ACE index & Simpson index \\
\hline P0 & 49534 & 1320 & 10.30 & 6421.45 & 7117.18 & 0.997 \\
\hline P1 & 44043 & 1270 & 10.09 & 6322.17 & 7250.18 & 0.997 \\
\hline P3 & 33788 & 1135 & 9.33 & 5723.52 & 6530.43 & 0.994 \\
\hline P4 & 36773 & 1363 & 9.84 & 5407.57 & 6428.06 & 0.997 \\
\hline
\end{tabular}

the bacterial communities could well represent the total sequences of the activated sludge samples. Based on a $97 \%$ similarity of sequences, the retrieved sequences were clustered into 1320, 1270, 1160, 1135 and 1363 operational taxonomic units (OTUs) at ZnO NP concentrations of 0, 0.25, 0.8, 1.5 and $4 \mathrm{mg} \mathrm{L}^{-1}$, respectively (Table 2).

The Shannon index, Simpson index, ACE index and Chao 1 index are commonly used for indicating the microbial diversity and richness. ${ }^{26}$ Compared with $0 \mathrm{mg} \mathrm{L}^{-1} \mathrm{ZnO}$ NPs, the Shannon, Chao 1 and ACE indexes showed significant changes at 1.5 and $4 \mathrm{mg} \mathrm{L}^{-1} \mathrm{ZnO}$ NPs (Table 2), suggesting that the presence of the ZnO NPs affected the microbial diversity and richness of the activated sludge in the OCO reactor.

3.2.2 Successional changes to the microbial community under ZnO NP stress. As the microbial diversity and richness of the activated sludge were impacted by the ZnO NPs, the microbial community patterns at the phylum level for each phase are further illustrated in Fig. 4. The prominent phyla of the five sludge samples consisted of Proteobacteria (38.2143.44\%), Bacteroidetes (27.47-43.36\%), Firmicutes (4.96$10.00 \%$ ), Chloroflexi (2.95-5.30\%), Acidobacteria (2.20-6.75\%), Actinobacteria (1.60-2.59\%), Cyanobacteria (0.61-1.67\%) and TM7 (0.17-1.74\%) at various ZnO NP concentrations. As the concentrations of the ZnO NPs increased from $0 \mathrm{mg} \mathrm{L}^{-1}$ to

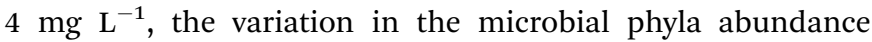
showed that the proportions of Proteobacteria, Firmicutes and Actinobacteria decreased slightly, whereas those of Bacteroidetes and Acidobacteria increased. Previous studies reported that Proteobacteria and Bacteroidetes were the predominant phyla in most full-scale WWTPs, ${ }^{27,28}$ together with the subdominant phyla Firmicutes and Acidobacteria. ${ }^{29}$ Specifically, Proteobacteria

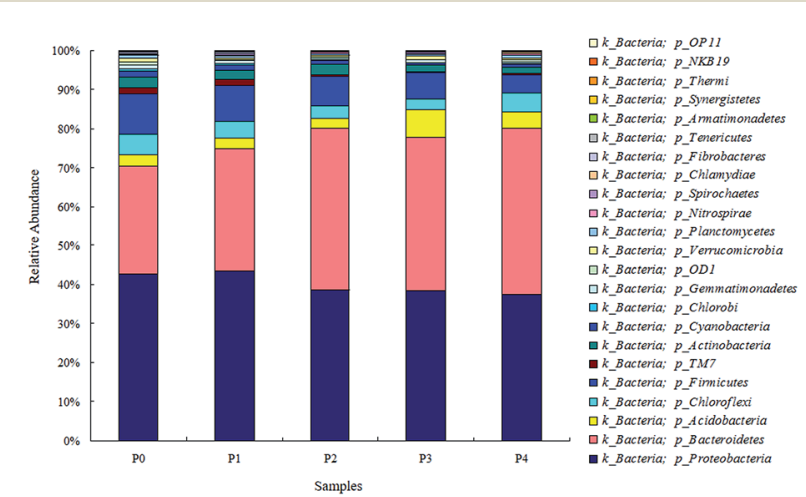

Fig. 4 Phylum-level distribution of microbial communities in the reactor. could play a crucial role in the removal of organic waste and nutrients. ${ }^{30,31}$ Chloroflexi are also common filamentous bacteria in the biological treatment processes of wastewater. ${ }^{32}$ At the genus level, Acinetobacter, Stenotrophomonas, Pseudomonas and Bacteroides decreased with increasing ZnO NP concentrations (Fig. 5). Previous studies showed that members of the genus Acinetobacter were typical bacteria present in sewage ${ }^{33}$ and versatile in the biodegradation of various pollutants, ${ }^{34}$ and Stenotrophomonas and Pseudomonas were classified as organophosphorus-degrading bacteria. ${ }^{35}$ On the other hand, Dechloromonas and Sediminibacterium firstly increased with increasing ZnO NP concentrations up to $1.5 \mathrm{mg} \mathrm{L}^{-1}$ (P0-P3), and decreased at the $\mathrm{ZnO} \mathrm{NP}$ concentration of $4 \mathrm{mg} \mathrm{L}^{-1}(\mathrm{P} 4)$. Previous reports illustrated that Dechloromonas were denitrifiers ${ }^{36}$ or capable of reducing nitrate or nitrite to nitrogen gas under autotrophic conditions. ${ }^{37}$ Dechloromonas also exhibited high tolerance to $\mathrm{ZnO}$ NPs in an $\mathrm{SBR}^{38}$ and an increasing tendency with elevated ZnO NP concentrations. ${ }^{39}$

Microbial similarities and differences of activated sludge samples were analyzed by a Venn diagram (Fig. 6). The total of observed OTUs in all five communities was 3074, but only 283 OTUs (9.2\%) of the total OTUs were shared among them (Fig. 6). The shared OTUs in the five communities indicated that some microbes existed in the activated sludge during the whole operational period. Furthermore, the majority of the shared OTUs at the phyla level were Proteobacteria (35.01\%) and Bacteroidetes (30.46\%), followed by Firmicutes (10.79\%), Chloroflexi (6.71\%) and Acidobacteria (2.64\%). The number of OTUs that were unique to each community were counted at 316 (P0), 283 (P1), 211 (P2), 262 (P3) and 484 (P4), and together they accounted for $90.8 \%$ of the total number of observed OTUs,

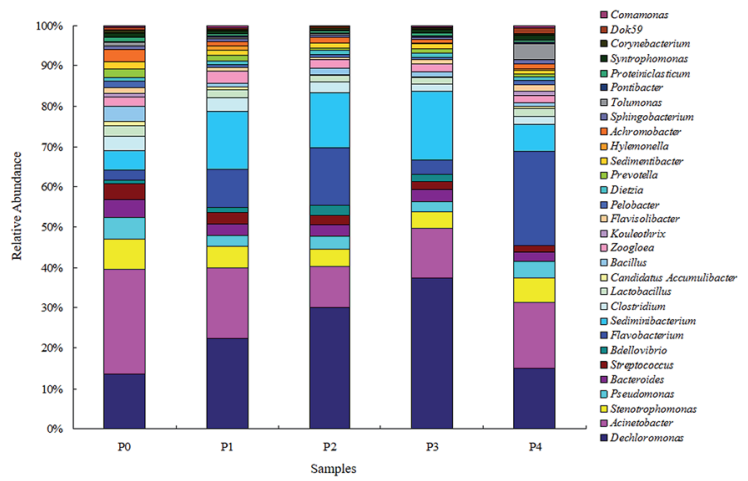

Fig. 5 Taxonomic classification of sequences at bacterial genus level in the dominated classes. 


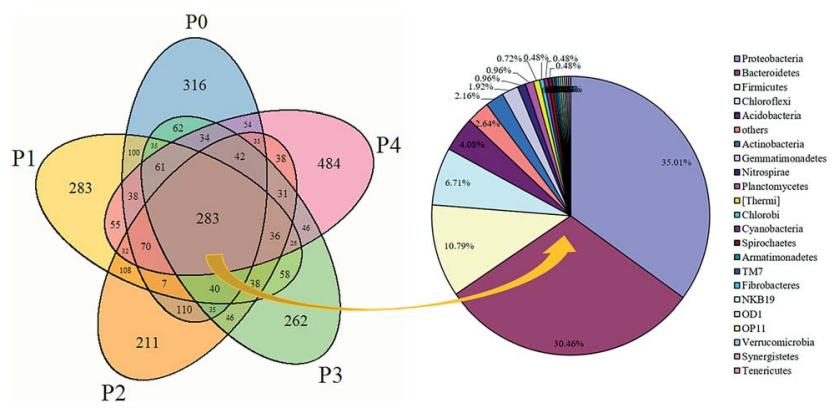

Fig. 6 Venn diagrams based on high-throughput sequencing of the microbial community at the P1-P4 stages (OTU at 3\% difference). The shared OTUs were analyzed at the phylum level.

suggesting that ZnO NPs altered the microbial community compositions with long-term exposure.

\section{Conclusions}

The long-term exposure of low-level ZnO NPs caused adverse impacts on the removal of nitrogen and phosphorus in an integrated OCO reactor. ZnO NPs resulted in the chronic decline of microbial diversity and richness. The shifts in the microbial communities revealed that Bacteroidetes and Proteobacteria were the predominant phyla, and even some common taxa existing in the activated sludge all the time experienced dramatic variations in the composition of the microbial species. The present results are significant in understanding the functional performance and microbial community successions of activated sludge under much lower ZnO NP stress.

\section{Conflicts of interest}

There are no conflicts to declare.

\section{Acknowledgements}

This research was supported by the National Natural Science Foundation of China (21777034), the China Scholarship Council (201708440543), the Natural Science Foundation of Guangdong Province, China (2014A030307019, 2015A030313801), the Science and Technology Planning Project of Guangdong Province, China (2014A020216046), the Special Innovation Project of Guangdong Colleges and Universities, China (2017KTSCX129), the Young Creative Talents Project of Department of Education of Guangdong Province (2015KQNCX102) and the Science and Technology Planning Project of Maoming (2014044).

\section{References}

1 Y. Yang, C. Zhang and Z. Hu, Environ. Sci.: Processes Impacts, 2013, 15, 39-48.

2 A. Nel, T. Xia, L. Mädler and N. Li, Science, 2006, 311, 622627.

3 F. Gottschalk, T. Sonderer, R. W. Scholz and B. Nowack, Environ. Sci. Technol., 2009, 43, 9216-9222.
4 T. Y. Sun, F. Gottschalk, K. Hungerbühler and B. Nowack, Environ. Pollut., 2014, 185, 69-76.

5 M. Li, L. Zhu and D. Lin, Environ. Sci. Technol., 2011, 45, 1977-1983.

6 Q. Chen, T. Li, M. Gui, S. Liu, M. Zheng and J. Ni, Bioresour. Technol., 2017, 239, 21-27.

7 Z. Wang, F. Huang, X. Mei, Q. Wang, H. Song, C. Zhu and Z. Wu, J. Membr. Sci., 2014, 471, 258-264.

8 X. Zhang, N. Zhang, H. Fu, T. Chen, S. Liu, S. Zheng and J. Zhang, Bioresour. Technol., 2017, 243, 93-99.

9 M. Tan, G. Qiu and Y.-P. Ting, Bioresour. Technol., 2015, 185, 125-133.

10 N.-Q. Puay, G. Qiu and Y.-P. Ting, J. Cleaner Prod., 2015, 88, 139-145.

11 J. W. Metch, N. D. Burrows, C. J. Murphy, A. Pruden and P. J. Vikesland, Nat. Nanotechnol., 2018, 13, 253-259.

12 D. Li, Y. Mao, Z. Liu, X. Yin, C. Lang and Y. Liu, Environ. Technol., 2014, 35, 2628-2633.

13 Z. Liu, H. Zhou, D. Li, X. Yin, Y. Mao and W. Chen, Technol. Water Treat., 2017, 43, 104-107.

14 APHA, Standard Methods for the Examination of Water and Wastewater, American Public Health Association/American Water Works Association/Water Environment Federation, Washington, DC, 2005.

15 J. G. Caporaso, J. Kuczynski, J. Stombaugh, K. Bittinger, F. D. Bushman, E. K. Costello, N. Fierer, A. G. Pena, J. K. Goodrich, J. I. Gordon, G. A. Huttley, S. T. Kelley, D. Knights, J. E. Koenig, R. E. Ley, C. A. Lozupone, D. McDonald, B. D. Muegge, M. Pirrung, J. Reeder, J. R. Sevinsky, P. J. Tumbaugh, W. A. Walters, J. Widmann, T. Yatsunenko, J. Zaneveld and R. Knight, Nat. Methods, 2010, 7, 335-336.

16 R. C. Edgar, B. J. Haas, J. C. Clemente, C. Quince and R. Knight, Bioinformatics, 2011, 27, 2194-2200.

17 Q. Wang, G. M. Garrity, J. M. Tiedje and J. R. Cole, Appl. Environ. Microbiol., 2007, 73, 5261-5267.

18 L. Lu, D. Xing and N. Ren, Water Res., 2012, 46, 2425-2434. 19 D. Q. Zhang, C. Y. Eng, D. C. Stuckey and Y. Zhou, Chemosphere, 2017, 171, 446-459.

20 A. Daverey, Y.-C. Chen, S. Sung and J.-G. Lin, Bioresour. Technol., 2014, 165, 105-110.

21 L. Hou, J. Xia, K. Li, J. Chen, X. Wu and X. Li, Water Sci. Technol., 2013, 67, 254-260.

22 S. T. Wang, S. P. Li, W. Q. Wang and H. You, RSC Adv., 2015, 5, 67335-67342.

23 E. Lombi, E. Donner, E. Tavakkoli, T. W. Turney, R. Naidu, B. W. Miller and K. G. Scheckel, Environ. Sci. Technol, 2012, 46, 9089-9096.

24 G. Liu, D. Wang, J. Wang and C. Mendoza, Sci. Total Environ., 2011, 409, 2852-2857.

25 F. Huang, Z. Wang, X. Mei and Z. Wu, Technol. Water Treat., 2013, 39, 14-18.

26 K. Meli, I. Kamika, J. Keshri and M. N. B. Momba, Sci. Rep., 2016, 6, 39176.

27 M. Hu, X. Wang, X. Wen and Y. Xia, Bioresour. Technol., 2012, 117, 72-79. 
28 D. Shu, Y. He, H. Yue and Q. Wang, Bioresour. Technol., 2015, 186, 163-172.

29 S. Xia, L. Duan, Y. Song, J. Li, Y. M. Piceno, G. L. Andersen, L. Alvarez-Cohen, I. Moreno-Andrade, C.-L. Huang and S. W. Hermanowicz, Environ. Sci. Technol., 2010, 44, 73917396.

30 C. O. Jeon, D. S. Lee and J. M. Park, Water Res., 2003, 37, 2195-2205.

31 Y. Yang, J. Quensen, J. Mathieu, Q. Wang, J. Wang, M. Li, J. M. Tiedje and P. J. J. Alvarez, Water Res., 2014, 48, 317-325. 32 L. Björnsson, P. Hugenholtz, G. W. Tyson and L. L. Blackall, Microbiology, 2002, 148, 2309-2318.
33 J. Snaidr, R. Amann, I. Huber, W. Ludwig and K. H. Schleifer, Appl. Environ. Microbiol., 1997, 63, 2884-2896.

34 S. i. Ishii, J. Koki, H. Unno and K. Hori, Appl. Environ. Microbiol., 2004, 70, 5026-5029.

35 B. K. Singh, Nat. Rev. Microbiol., 2009, 7, 156-164.

36 K. Heylen, B. Vanparys, L. Wittebolle, W. Verstraete, N. Boon and P. De Vos, Appl. Environ. Microbiol., 2006, 72, 2637-2643.

37 J. Ma, Z. Wang, D. He, Y. Li and Z. Wu, Water Res., 2015, 78, 98-110.

38 Z. Liu, H. Zhou, J. Liu, X. Yin, Y. Mao, Z. Liu, Z. Li and W. Xie, RSC Adv., 2016, 6, 110108-110111.

39 S. Wang, M. Gao, Z. She, D. Zheng, C. Jin, L. Guo, Y. Zhao, Z. Li and X. Wang, Bioresour. Technol., 2016, 216, 428-436. 